\title{
1 Innolysins: A novel approach to engineer endolysins to kill Gram-negative bacteria
}

2 Athina Zampara ${ }^{\mathrm{a}}$, Martine C. Holst Sørensen ${ }^{\mathrm{a}}$, Dennis Grimon ${ }^{\mathrm{b}}$, Fabio Antenucci ${ }^{\mathrm{a}}$, Yves Briers ${ }^{\mathrm{b}}$ and

3 Lone Brøndsted ${ }^{\text {a\# }}$

4

5 Department of Veterinary and Animal Sciences, University of Copenhagen, Stigbøjlen 4, 1870

6 Frederiksberg C, Denmark ${ }^{\mathrm{a}}$; Department of Biotechnology, Ghent University, Valentin

$7 \quad$ Vaerwyckweg 1, 9000 Gent, Belgium ${ }^{\text {b }}$

8

9 Running Head: Innolysins target Gram-negative bacteria

10 \#Address correspondence to Lone Brøndsted: $\underline{\text { lobr@sund.ku.dk }}$

11 Keywords: endolysins, receptor binding proteins, engineering, outer membrane, Gram-negative

12 bacteria 


\section{ABSTRACT}

14 Bacteriophage-encoded endolysins degrading the essential peptidoglycan of bacteria are promising alternative antimicrobials to handle the global threat of antibiotic resistant bacteria. However, endolysins have limited use against Gram-negative bacteria, since their outer membrane prevents access to the peptidoglycan. Here we present Innolysins, a novel concept for engineering endolysins that allows the enzymes to pass through the outer membrane, hydrolyse the peptidoglycan and kill the target bacterium. Innolysins combine the enzymatic activity of endolysins with the binding capacity of phage receptor binding proteins (RBPs). As our proof of concept, we used phage T5 endolysin and receptor binding protein $\mathrm{Pb} 5$, which binds irreversibly to the phage receptor FhuA involved in ferrichrome transport in Escherichia coli. In total, we constructed twelve Innolysins fusing endolysin with $\mathrm{Pb} 5$ or the binding domain of $\mathrm{Pb} 5$ with or without flexible linkers in between. While the majority of the Innolysins maintained their muralytic activity, Innolysin\#6 also showed bactericidal activity against $E$. coli reducing the number of bacteria by $1 \log$, thus overcoming the outer membrane barrier. Using an E. coli fhuA deletion mutant, we demonstrated that FhuA is required for bactericidal activity, supporting that the specific binding of $\mathrm{Pb} 5$ to its receptor on $E$. coli is needed for the endolysin to access the peptidoglycan. Accordingly, Innolysin\#6 was able to kill other bacterial species that carry conserved FhuA homologs such as Shigella sonnei and Pseudomonas aeruginosa. In summary, the Innolysin approach expands recent protein engineering

31 strategies allowing customization of endolysins by exploiting phage RBPs to specifically target 32 Gram-negative bacteria. 


\section{IMPORTANCE}

34 The extensive use of antibiotics has led to the emergence of antimicrobial resistant bacteria

35 responsible for infections causing more than 50,000 deaths per year across Europe and the US. In

36 response, the World Health Organization has stressed an urgent need to discover new antimicrobials

37 to control in particular Gram-negative bacterial pathogens, due to their extensive multi-drug

38 resistance. However, the outer membrane of Gram-negative bacteria limits the access of many

39 antibacterial agents to their targets. Here, we developed a new approach, Innolysins that enable

40 endolysins to overcome the outer membrane by exploiting the binding specificity of phage receptor

41 binding proteins. As proof of concept, we constructed Innolysins against $E$. coli using the endolysin

42 and the receptor binding protein of phage T5. Given the rich diversity of phage receptor binding

43 proteins and their different binding specificities, our proof of concept paves the route for creating an

44 arsenal of pathogen specific alternative antimicrobials. 


\section{INTRODUCTION}

The limited permeability of the outer membrane is a major obstacle for development of novel antimicrobials against Gram-negative pathogens preventing many compounds from reaching their intracellular targets (1). Bacteriophages (phages), viruses that infect bacteria, have naturally evolved mechanisms to overcome the outer membrane to infect their bacterial hosts $(2,3)$. In the first step of infection, phages bind to host cells and inject their genetic material across the outer and inner membrane of the bacterial cells into the cytoplasm. Also, during the final stage of the lytic infection cycle, phages produce proteins within the cell, which destroy the bacterial cell wall, leading to cell lysis. Thus, the molecular tools developed during phage evolution may be exploited to develop novel phage-based antimicrobials that are able to pass the outer membrane and to kill Gram-negative bacteria.

Phages recognize their host bacteria by binding to specific surface receptors that may be outer membrane proteins, lipopolysaccharides or components of bacterial capsules, pili and flagella (4). The adhesion specificity is mediated by receptor binding proteins (RBPs) that form fibers or spikes at the distal phage tail. A well-characterized RBP is Pb5, located at the tail tip of the phage T5, which specifically binds to the bacterial receptor FhuA during infection of the E. coli host $(5,6)$.

61 FhuA is an outer membrane protein that actively transports siderophore-ferrichrome and allows $E$. coli to take up iron from the environment. The crystal structure of FhuA reveals two domains, a 22stranded anti-parallel barrel that forms a hollow channel with eleven surface-exposed loops and a globular domain, known as the plug, which blocks the channel in its inactive state $(7,8)$. Previously it was shown that $\mathrm{Pb} 5$ of phage T5 binds irreversibly to the extracellular loop L4 and the plug of FhuA. In addition, it was proposed that FhuA acts as an anchor for phage T5 binding to E. coli, subsequently allowing the tail fiber composed of $\mathrm{Pb} 2$ to transverse the outer membrane and inject the DNA $(9,10)$. 
69 During the last stage of phage infection, phages produce endolysins to lyse the bacterial cells and release progeny phages. Endolysins are hydrolytic enzymes that, after gaining access to the

71 periplasm, degrade the peptidoglycan, leading to cell lysis (11). Endolysins may have different catalytic activities, depending on the bond that they target in the peptidoglycan, and are classified as glycosidases, amidases or endopeptidases. The endolysin encoded by phage T5 is a well characterized endopeptidase that hydrolyzes the bond between L-alanine and D-glutamic acid of the peptidoglycan in E. coli (12). While native endolysins have been successfully applied as antimicrobials against Gram-positive bacteria including Staphylococcus aureus and streptococci, the outer membrane of Gram-negative bacteria generally prevents access to the peptidoglycan layer (13). To enable killing of Gram-negative pathogens using endolysins, a number of engineering strategies have been proposed. Recently it was shown that the fusion of endolysins to polycationic or amphipathic peptides enables the endolysins to pass the outer membrane and kill multi-drug resistant Pseudomonas aeruginosa and Acinetobacter baumannii (14). Furthermore, recombinant T4 lysozyme carrying the binding domain of pesticin, targeting the outer-membrane protein FyuA, has been shown to kill Yersinia and pathogenic E. coli strains (15). Similarly, fusion of the E. coli phage endolysin Lysep3 with the translocation and receptor-binding domain of another bacteriocin colicin A, targeting the outer membrane protein BtuB could kill E. coli (16). Thus, these studies have demonstrated that endolysins can be engineered to pass the outer membrane and subsequently kill Gram-negative bacteria.

Here, we expand on the concept of delivering endolysins across the Gram-negative outer membrane by combining the specificity of phage RBPs with the antimicrobial activity of endolysins into RBPendolysin hybrids (Innolysins). To provide a proof of concept, we utilize the endolysin and the RBP

91 (Pb5) of phage T5. Pb5 was selected among many phage RBPs due to the specific and stable 
bioRxiv preprint doi: https://doi.org/10.1101/408948; this version posted September 6, 2018. The copyright holder for this preprint (which was not certified by peer review) is the author/funder. All rights reserved. No reuse allowed without permission.

93 the periplasm, where it can degrade the peptidoglycan. This engineering approach has the potential

94 to utilize multiple distinct phage-derived RBPs to customize the bactericidal spectrum of Innolysins

95 against diverse Gram-negative bacteria. 


\section{RESULTS}

\section{Strategy for construction of Innolysins}

To construct Innolysins, we combined the RBP of phage T5 (Pb5) with the phage T5 endolysin (T5 Lys) for targeted delivery of the endolysin. The binding domain of $\mathrm{Pb} 5$ has previously been shown to be located in the N-terminus (488aa) of the protein (17). To determine whether the binding domain of the Pb5 is sufficient to enable the endolysin to pass through the outer membrane, we fused $\mathrm{T} 5$ endolysin with both the entire $\mathrm{Pb} 5$ and with the $\mathrm{Pb} 5$ binding domain $\left(\mathrm{Pb} 5_{1-488}\right)$. We anticipated that antimicrobial activity of an Innolysin requires both that $\mathrm{Pb} 5$ is able to bind to the outer membrane protein FhuA, and that the fused phage T5 endolysin is translocated across the outer membrane and remains active to degrade the peptidoglycan. Thus, to ensure that the joined domains remain functional after fusion, we either fused them directly or added linkers in between. We used flexible linkers composed of small non-polar amino acids, glycine and alanine, providing a certain degree of movement of the fused domains (18). To optimize the two-domain cooperation, we used linkers of two different sizes, L1 composed of six amino acids and L2 that consists of fourteen amino acids. In addition, to investigate the optimal orientation of the endolysin and RBP domains, we constructed the Innolysins in two directions with and without linkers (Fig. 1). As such, a total of twelve Innolysins were constructed.

\section{Innolysins show muralytic activity}

To demonstrate that the muralytic activity of the endolysin is maintained after the fusion with the RBP and a linker, the fused proteins were expressed in E. coli BL21 and supernatants of cell lysates were tested for muralytic activity. A standardized assay for analysis of the muralytic activity of endolysins acting against peptidoglycan of Gram-negative bacteria was used, based on outer membrane permeabilized $P$. aeruginosa cells, which share a common peptidoglycan chemotype (A1 $\gamma$ ) with E. coli (19). The majority of Innolysins (nine out of twelve) were active with enzymatic 
activity ranging between 126-771 U/ml. Innolysin\#9 (Pb5-L1-T5Lys) showed the highest activity per $\mathrm{ml}$ cleared lysate, reaching the muralytic activity of phage $\mathrm{T} 5$ endolysin alone (795 U/ml) (Fig. and $\mathrm{Pb} 5$ alone did not show any significant activity compared to the negative control (muralytic activity of supernatant cell lysates carrying the empty vector, pVTSD2). Interestingly, both Innolysin\#1 and \#3 were composed of phage $\mathrm{T} 5$ endolysin and the whole $\mathrm{Pb} 5$ protein, fused in two opposite directions without a linker. Overall, the majority of hybrid endolysins showed muralytic activity after fusion with $\mathrm{Pb} 5$ either in the $\mathrm{N}$ - or $\mathrm{C}$-terminus, while the presence of a flexible linker enhanced the activity of the engineered proteins.

\section{Innolysin\#6 inhibits $E$. coli growth}

To assess whether binding of $\mathrm{Pb} 5$ allowed the fused endolysin to get access to the peptidoglycan, we screened the muralytically active Innolysins for their ability to inhibit growth of the phage T5 bacterial host E. coli ATCC11303. ATCC11303 was mixed with supernatants of cell lysates of strains expressing Innolysins, and bacterial growth was measured spectrophotometrically after $18 \mathrm{~h}$

134 (Fig. 3). Growth inhibition was determined as the lack of growth of a start inoculum treated with an Innolysin compared to the negative control (growth of ATCC11303 cells treated with supernatant lysates of cells carrying the empty vector, pVTSD2). A significant inhibitory activity was noticed when E. coli ATCC11303 was treated with Innolysin\#6 similar to the positive control, Art-175, an engineered endolysin that was previously shown to have both an inhibitory and bactericidal effect against $E$. coli $(20,21)$. The remaining eight Innolysins, $\mathrm{Pb} 5$ or endolysin alone did not significantly affect the E. coli growth compared to the negative control (Fig. 3). The screening resulted in one

141 promising antimicrobial candidate out of the twelve Innolysins that could inhibit E. coli growth, 142 indicating that domains have to be fused in a specific order and with a specific linker to acquire 143 antibacterial activity after fusion. The active variant was composed of $\mathrm{T} 5$ endolysin in the $\mathrm{N}$ - 
144 terminus linked by a six amino-acid linker to the $\mathrm{Pb} 5_{1-488}$ in the $\mathrm{C}$-terminus. This result indicates that the binding domain of $\mathrm{Pb} 5$ alone can target the bacterial cells and allow phage $\mathrm{T} 5$ endolysin to overcome the outer membrane and inhibit E. coli growth.

\section{Killing efficiency of Innolysin\#6 requires FhuA, but not energy}

To determine whether binding of $\mathrm{Pb5}$ to FhuA is required for the antimicrobial activity of

149 Innolysin\#6, killing efficiency of the purified hybrid protein was tested on a fhuA deletion mutant in 150 E. coli BL21 and compared to the wild type E. coli BL21 and E. coli ATCC11303. Bacterial cells 151 were incubated with the purified Innolysin at a final concentration of $0.2 \mathrm{mg} / \mathrm{ml}$ and the reduction in cell counts was compared to the non-treated cells (Fig. 4). E. coli BL21 cell counts were reduced by $1.22 \pm 0.12 \log$ after Innolysin treatment and a similar decrease was noticed in E. coli ATCC11303 cells $(1.09 \pm 0.15 \log$ reduction), without prior optimization. No significant effect of the Innolysin was shown in E. coli BL21 $f$ fhuA, supporting our hypothesis that the Innolysin leads to ferrichrome requires energy from the cytoplasmic proton motive force transduced to the outer membrane via the TonB protein, phage T5 interacts with FhuA independent of TonB $(8,22)$. To determine whether activity of Innolysin\#6 requires such energy, bactericidal activity was tested against an E. coli tonB deletion mutant (ECOR4AtonB) and the wild type ECOR4 as a positive control (Fig 4). As expected, TonB was not required for bactericidal activity of the Innolysin (Fig. transported passively through the outer membrane and target the peptidoglycan, leading to killing of E. coli.

\section{Morphological changes in cells treated with Innolysin}

166 Transmission Electron Microscopy (TEM) analysis was performed to determine the effects of 
BL21 4 fhuA was visualized after incubation with Innolysin\#6 for $15 \mathrm{~min}$ and compared to untreated cells (Fig. 5). Almost all untreated cells were intact with normal cell envelope morphology. In contrast, treatment of E. coli BL21 with Innolysin\#6 led to cell integrity damage in the majority of cells with cytosol leakage occurring mainly at the poles. Furthermore, periplasmic space appeared to widen with the outer membrane disconnecting from the inner membrane and cell debris could be detected likely due to cell lysis. This dramatic effect on cell morphology was not observed on $E$. coli BL21 4 fhuA treated with Innolysin\#6, where only a low increase in damaged cells was noticed compared to the untreated cells. These observations demonstrate that Innolysin\#6 acts rapidly by interfering with membrane integrity, while presence of FhuA is required for Innolysin to exert high antimicrobial activity.

\section{Innolysin targets FhuA homologs of other than $E$. coli species}

179 To investigate whether the constructed Innolysin\#6 could target FhuA homologs in other species, we tested the killing activity of the purified engineered protein against Shigella sonnei, Salmonella Typhimurium LT2c and Pseudomonas aeruginosa PAO1 (Fig. 6). These bacteria carry FhuA homologs with identity ranging between 22.6 and $99.6 \%$ to the FhuA of E. coli BL21 (see Table S2 in the supplemental material). The Innolysin killed S. sonnei (99.6\% FhuA identity at the protein level) and $P$. aeruginosa PAO1 (less than 39\% FhuA identity), leading to average log reductions in cell number of $1.52 \pm 0.14$ and $1.03 \pm 0.25$, respectively. In contrast, no significant reduction of in this strain and FhuA of E. coli BL21 (76.53\% FhuA identity). Alignment of FhuA homologs

188 showed that in comparison to FhuA of S. sonnei and E. coli, FhuA of Salmonella Typhimurium 189 LT2c lacks 17 amino acids which are part of the surface-exposed L4 loop of E. coli FhuA (Fig. 7) 190 (8). P. aeruginosa PAO1 lacks FhuA, however, it harbors other outer membrane proteins involved 191 in the bacterial iron-uptake, including FpvA, FpvB, FptA, FiuA and FoxA (23). Alignment of $E$. 
192 coli FhuA with these proteins revealed a low percent identity ranging between 22.61 and $38.52 \%$ 193 (see Table S2). Notably, the amino-acid sequence responsible for L4 loop formation of FhuA 194 aligned to parts of the outer membrane proteins FptA and FpvA of $P$. aeruginosa (Fig. S1) which, 195 based on their tertiary structure predictions, form surface-exposed loops $(24,25)$. This observation 196 suggests that such loops may interact with the Innolysin. In summary, we conclude that the 197 Innolysin can target FhuA homologs in other than E. coli species. 


\section{DISCUSSION}

199 Phages have developed unique and complex mechanisms to infect and lyse bacteria. In the first 200 stage of infection, phages utilize receptor binding proteins (RBPs) to target specific bacterial host 201 receptors on the cell surface, whereas at later stages phage endolysins degrade the peptidoglycan 202 layer inducing lysis and progeny release. Here, we exploit the binding capacity of a phage RBP to 203 enable an endolysin to bypass the outer membrane of Gram-negative bacteria and to gain access to 204 peptidoglycan. As proof of concept, we have utilized the phage T5 endolysin and its receptor 205 binding protein $\mathrm{Pb} 5$ and constructed twelve Innolysins by fusing the endolysin with the whole Pb5 206 or with only the binding domain of $\mathrm{Pb} 5$ in different orientations, with or without linkers. The 207 majority of the novel Innolysins maintained their muralytic activity and Innolysin\#6 also displayed 208 antimicrobial activity against $E$. coli. Our work expands the concept of developing alternative 209 antimicrobials based on enzyme fusions and demonstrates that a phage RBP efficiently can be used 210 to target antimicrobial enzymes selectively to Gram-negative bacterial species.

211 Here we showed that the bactericidal activity of Innolysin\#6 consisting of T5 endolysin, a small 212 linker and the binding domain of Pb5, is dependent on FhuA receptor of phage T5 $(5,6)$. Similar to 213 phage T5 binding and DNA injection $(22,26,27)$, the antimicrobial activity of Innolysin\#6 is 214 independent of energy provided by TonB, indicating that Innolysin\#6 is passively transported to the 215 peptidoglycan. Microscopic analysis revealed that Innolysin\#6 causes cytosol leakage mainly from 216 the bacterial poles of wild type E. coli encoding FhuA. Interestingly, several phages have been 217 shown to preferentially adsorb at the bacterial poles, including E. coli phage $\varphi 80$ that uses FhuA as 218 receptor (28). Thus, Innolysin\#6 may bind to FhuA of E. coli in a similar manner as phage T5 219 causing specific lysis of cells carrying the FhuA receptor of $\mathrm{Pb}$ 5.

220 Since FhuA is the binding target of Innolysins and works as a transport channel for uptake of 
221 ferrichrome, it is tempting to speculate that Innolysin is transported passively through the channel.

222 Yet, it has been shown that Pb5 binding to FhuA does not allow the channel to open $(5,9)$ and 223 similarly binding of Innolysin may not provide the conformational changes needed for the FhuA 224 channel to open. In addition, the size of the unplugged channel $(2.5 \mathrm{~nm})$ appears to be too narrow 225 for the Innolysin $(67.62 \mathrm{kDa})$ to pass (29), indicating that partial unfolding is required for the 226 Innolysin to overcome the size restraint by FhuA. Lukacik and co-workers showed that a hybrid 227 lysin consisted of the phage T4 lysozyme and the binding domain of pesticin targeting FyuA could reach the peptidoglycan (15). But similar to Innolysins, the dimensions of the FyuA pore do not permit passage of the hybrid T4 lysozyme without unfolding. Yet, it was demonstrated that unfolding of the enzymatic domain is not required for activity (15), indicating that such hybrid endolysins may overcome the outer membrane by other means than passing through the targeted channels.

Alternatively, Innolysins may access the peptidoglycan by interfering with the membrane integrity. FhuA has been proposed to work as an anchor for phage T5 by an irreversible binding of $\mathrm{Pb} 5$ to the FhuA receptor (10). In Innolysins we combine $\mathrm{Pb5}$ with phage $\mathrm{T} 5$ endolysin that is a globular endolysin carrying a single enzymatically active domain with limited intrinsic antimicrobial activity (30). Thus, we equipped a globular endolysin with a binding domain using a phage RBP and transformed a globular endolysin into a novel engineered modular endolysin. In comparison to globular endolysins, modular endolysins composed of catalytic domain(s) and a cell wall binding domain display up to five times higher enzymatic activity $(31,32)$. Thus, by irreversible binding to 241 FhuA (5), Pb5 may bring the Innolysin in close proximity to the outer membrane, enhancing the 242 antibacterial activity of the endolysin. The binding of the Innolysin could interfere with phosphates 243 in the outer membrane lipopolysaccharides and displace the stabilizing $\mathrm{Mg}^{2+} / \mathrm{Ca}^{2+}$ ions due to the 244 high isoelectric point of phage T5 endolysin (7.91), thus destabilizing the ionic forces in the outer 
membrane (33). A similar mode of action has been described for Artilysins, endolysins engineered with polycationic or amphipathic peptides that destabilize the outer membrane and target the endolysins to peptidoglycan (14). Furthermore, we found that a linker between the T5 endolysin and $\mathrm{Pb} 5_{1-488}$ components is essential for bactericidal activity. Similarly, modular endolysins contain flexible interdomain linkers, which are important for enzyme activity (34). Thus, the linker may be necessary for the Innolysin to properly bind to the receptor FhuA, interfere with the membrane integrity and overcome the outer membrane.

FhuA is conserved in bacterial species including Escherichia, Shigella and Salmonella and is structurally homologous to other Ton-B dependent outer membrane receptors involved in bacterial iron uptake (35). The Innolysin showed antimicrobial activity towards Shigella sonnei and Pseudomonas aeruginosa, whereas Salmonella Typhimurium LT2c was not sensitive to the Innolysin. While $S$. sonnei and $P$. aeruginosa encode homologs or equivalents of FhuA and share a conserved L4 loop, shown to be the binding target of phage T5 $(22,26)$, Salmonella FhuA lacks the L4 loop. Thus, the L4 loop of FhuA may be required for the antimicrobial activity of the Innolysin, enabling efficient binding of $\mathrm{Pb} 5$ to its cognate receptor. However, since FhuA is a phage receptor, common phage adsorption blocking mechanisms, such as receptor masking by lipopolysaccharides 261 or downregulation of receptor expression $(36,37)$ could also play a role in Innolysin resistance in Salmonella.

263 In this study, we used the binding specificity of the phage T5 receptor binding protein to its cognate

264 FhuA receptor to deliver an endolysin across the outer membrane and target the peptidoglycan. 265 Compared to bacteriocin-derived fusions with endolysins, the natural diversity of phage RBPs 266 greatly expands the potential of designing novel antimicrobials targeting a wide range of Gram267 negative bacterial species. As opposed to some bacteriocins and traditional antibiotics, Innolysins 
268 can target non-actively growing bacteria, since they bypass the outer membrane passively (38). 269 Additionally, Innolysins can be designed to target important virulent determinants such as OmpX in 270 Escherichia coli and Ail in Yersinia pestis, in order to modulate virulence $(39,40)$. Although 271 further experiments are needed for optimizing the activity of such antimicrobials and for elucidating 272 the exact mechanism by which Innolysins bypass the outer membrane, our findings provide a 273 promising approach to design novel therapeutic agents with a highly customizable bactericidal spectrum.

MATERIAL AND METHODS

\section{Bacterial strains}

E. coli BL21-CodonPlus-(DE3)-RIL (Agilent Technologies) was used for expression of recombinant proteins. Inhibition assays were conducted with E. coli ATCC11303 (Leibniz Institute). E. coli BL21 (DE3) (Agilent Technologies), E. coli ECOR4 (STEC Center at Michigan 280 State University), Shigella sonnei (41), Pseudomonas aeruginosa PAO1 (42) and Salmonella 281 Typhimurium LT2c (43) were used for the bactericidal assay. Deletions of the fhuA and tonB genes 282 on the chromosomes of E. coli BL21 (DE3) and E. coli ECOR4, respectively, were previously 283 generated by the Lambda red recombination system as described before (44). Briefly, the 284 kanamycin cassette from plasmid pKD4 was amplified ( $P f u$ polymerase; Thermo Fisher Scientific, 285 Waltham, MA) with oligonucleotides carrying $\sim 39$ nucleotide extensions homologous to regions 286 adjacent to the target gene (custom primers, Table S1). The amplicon was purified with QIAquick 287 PCR Purification Kit (Qiagen) and electroporated into competent cells. Kanamycin-resistant clones 288 were selected and insertion of the kanamycin cassette was verified by PCR. 


\section{Cloning of constructs}

290 Genomic material was purified from phage T5 (Leibniz Institute) and used as a template for 291 amplification (Pfu polymerase; Thermo Fisher Scientific, Waltham, MA) of the genes encoding T5 292 endolysin (YP_006868.1) or Pb5 (YP_006985.1) with specific primers (Table S1). The linkers were 293 created as primer cassettes. The specific primers were mixed, heated to $95^{\circ} \mathrm{C}$ and gradually cooled 294 down for hybridization. Each assembly encoding the different fragments of the fusion proteins was constructed by Type IIs cloning. Amplicons or primer cassettes (each $50 \mathrm{ng} / \mu \mathrm{l}$ ) were mixed with $100 \mathrm{ng} / \mu \mathrm{l}$ pNICBsa4, in which the N-terminal His-tag was exchanged for a C-terminal His-tag, and BsaI and T4 DNA ligase were added. The mixture was incubated alternatingly at $37^{\circ} \mathrm{C}$ and $16^{\circ} \mathrm{C}$ (50 cycli) and heat inactivated at $80^{\circ} \mathrm{C}$. Transformation of $E$. coli BL21-CodonPlus-(DE3)-RIL was 299 conducted and transformants were selected in the presence of kanamycin $(100 \mu \mathrm{g} / \mathrm{ml})$ and 300 chloramphenicol $(50 \mu \mathrm{g} / \mathrm{ml})$.

\section{1}

302

303

\section{Protein expression and purification}

Recombinant proteins were simultaneously expressed in a 96 deep-well plate. Freshly transformed colonies were resuspended in $500 \mu \mathrm{l}$ of auto-induction medium (93\% ZY medium, $0.05 \% 2 \mathrm{M}$ $\mathrm{MgSO}_{4}, 2 \% 50 \mathrm{x} 5052,5 \%$ 20x NPS) and incubated at $37{ }^{\circ} \mathrm{C}$ for 5 hours, followed by $16^{\circ} \mathrm{C}$ for 40 hours, both at $900 \mathrm{rpm}$. Cells were spun down by centrifugation $\left(3,200 \times g, 30 \mathrm{~min}, 4^{\circ} \mathrm{C}\right)$ and the supernatants were removed. Cell pellets were lysed by exposure to chloroform vapor, by placing the deep-well plate upside-down in a glass petri dish containing chloroform-saturated filters for $2 \mathrm{~h}$. Cell lysates were resuspended in $20 \mathrm{mM}$ HEPES-NaOH (pH 7.4), and $1 \mathrm{U}$ DNase I, followed by incubation $\left(100 \times \mathrm{rpm}, 1\right.$ hour, $\left.30^{\circ} \mathrm{C}\right)$. Insoluble fractions of cell lysates were removed by centrifugation $\left(3,200 \times g\right.$ for $30 \mathrm{~min}$, at $\left.4^{\circ} \mathrm{C}\right)$ and the supernatants containing the soluble fractions of the lysates were screened for both muralytic and inhibitory activities. 
312 For large-scale expression of the Innolysin\#6, a 1 L expression culture (LB medium) was induced

313 with $1 \mathrm{mM}$ isopropyl-beta-D-thiogalactopyranoside (Thermo Fisher Scientific) in the mid-

314 logarithmic phase $\left(\mathrm{OD}_{600}=0.6\right)$. Incubation of the culture was followed at $16^{\circ} \mathrm{C}$ for eighteen hours at $315120 \mathrm{rpm}$. Cells were harvested by centrifugation $\left(8,000 \times g, 10 \mathrm{~min}, 4^{\circ} \mathrm{C}\right)$ and the cell pellet was 316 resuspended in $10 \mathrm{ml}$ of lysis buffer $\left(20 \mathrm{mM} \mathrm{NaH} \mathrm{PO}_{4}-\mathrm{NaOH}, 0.5 \mathrm{M} \mathrm{NaCl}, 50 \mathrm{mM}\right.$ imidazole, $\mathrm{pH}$ 317 7.4), followed by sonication (Bandelin Sonopul HD 2070 homogeniser) with 10 bursts of $30 \mathrm{sec}$ 318 (amplitude of 50\%) with $30 \mathrm{sec}$ intervals. Protein lysate was double-filtered using filters with pore 319 size of $0.22 \mu \mathrm{m}$. His GraviTrap ${ }^{\mathrm{TM}}$ gravity flow columns (GE Healthcare) were used for His-tagged 320 protein purification according to the manufacturer's instructions. Buffer exchange was performed 321 with $20 \mathrm{mM}$ HEPES-NaOH (pH 7.4) by using Amicon ${ }^{\mathrm{R}}$ Ultra - 4 centrifugal filters with $50 \mathrm{kDa}$ 322 cutoff (Merck Millipore) and protein concentration was measured by Qubit ${ }^{\mathrm{TM}}$ Protein Assay Kit (Q33211) in Qubit 2.0 Fluorometer (Invitrogen, Q32866).

\section{4}

\section{Muralytic assay}

Analysis of the muralytic activity was conducted as described before $(14,45)$ using outer membrane permeabilized $P$. aeruginosa PAO1 cells as substrate. Briefly, exponentially growing cells $\left(\mathrm{OD}_{600}=\right.$ 0.6) were harvested by centrifugation $\left(3,200 \times g, 30 \mathrm{~min}, 4^{\circ} \mathrm{C}\right)$ and permeabilized by resuspension in chloroform-saturated $0.05 \mathrm{M}$ Tris- $\mathrm{HCl}(\mathrm{pH} \mathrm{7.7)}$ and gentle shaking for $45 \mathrm{~min}$. To remove chloroform traces, cells were washed twice with phosphate-buffered saline (PBS, $\mathrm{pH} 7.4)$ and further concentrated to $\mathrm{OD}_{600}=1.5 .30 \mu \mathrm{l}$ of the soluble lysate fractions was added on top of $270 \mu \mathrm{l}$ of the substrate. Supernatants of lysates of cells expressing the phage T5 endolysin or carrying an empty vector (pVTSD2) were used as positive and negative controls, respectively. Turbidities were measured spectrophotometrically at $655 \mathrm{~nm}$ every 30s for one hour by a Microplate Reader 680 system (Bio-Rad). Muralytic activities were calculated by a previously described standardized 
method (46).

\section{6}

\section{Antibacterial assay}

345 Gram-negative, exponentially growing cells $\left(\mathrm{OD}_{600}=0.6\right)$ were diluted 100 -fold in $20 \mathrm{mM}$ HEPES$346 \mathrm{NaOH}(\mathrm{pH}$ 7.4). $100 \mu \mathrm{l}$ of the diluted cell suspensions were mixed with $100 \mu \mathrm{l}$ of the pure Innolysin 347 at a final concentration of $0.2 \mathrm{mg} / \mathrm{ml}$. $100 \mu \mathrm{l}$ of $20 \mathrm{mM}$ HEPES-NaOH (pH 7.4) was added to the 348 cells as a negative control. The samples were incubated for $30 \mathrm{~min}$ at $20^{\circ} \mathrm{C}$, and appropriate cell 349 dilutions were plated on LB (Lysogeny Broth) agar plates in triplicate. After overnight incubation at

\section{Growth inhibition assay}

E. coli ATCC11303 cells were used for the growth inhibition assay. Overnight cell cultures prepared in Mueller Hinton $(\mathrm{MH})$ broth were adjusted to $\mathrm{OD}_{600}=0.1$ in $2 \mathrm{xMH}$ and further 100-fold diluted in $2 \mathrm{xMH}$. $50 \mu \mathrm{l}$ of the cell suspension was mixed with $50 \mu \mathrm{l}$ of the soluble lysate fraction. Art-175 $(0.1 \mathrm{mg} / \mathrm{ml})$ and the soluble lysate fraction of cells carrying an empty vector were mixed with cells as positive and negative controls, respectively. Endpoint measurement was performed spectrophotometrically at $655 \mathrm{~nm}$ after exactly $18 \mathrm{~h}$ incubation at $37^{\circ} \mathrm{C}$. All experiments were done in triplicate.

\section{dilutions were plated on LB (Lysogeny Broth) agar plates in thiplicate. After overnight incubation at} $37^{\circ} \mathrm{C}$, colony forming units (CFU) were counted and cell concentrations ( $\left.\mathrm{CFU} / \mathrm{ml}\right)$ were calculated. Experiments were conducted three independent times. The antibacterial activity was determined based on the difference of the average logarithmic cell concentrations of the treated samples compared to the negative control.

\section{Transmission Electron Microscopy}

$1 \mathrm{ml}$ of exponentially growing cells were harvested by centrifugation (10000 rpm, $5 \mathrm{~min}$ ) and resuspended in $200 \mu 1$ of HEPES buffer ( $\mathrm{pH}$ 7.4). This washing procedure was repeated 3 times, 
after which the cell pellets were resuspended in either $50 \mu \mathrm{l}$ of HEPES buffer or the Innolysin\#6 and incubated for 15 minutes at $20^{\circ} \mathrm{C}$. Samples were negatively stained with $2 \%$ uranyl-acetate on glow-discharged continuous carbon-coated 300-mesh copper grids (EM Resolutions Ltd). Transmission electron microscopy was performed on a Philips CM100 (Tungsten emitter) electron microscope operating at $100 \mathrm{kV}$. Images were recorded on a side-mounted Olympus Veleta (2048 x 2048 pixels) charge-coupled device camera via the iTEM software.

\section{Bioinformatic analysis}

To identify FhuA homologs, we used the FhuA protein sequence of E. coli BL21 (WP_000124402.1) to search homologous proteins in the National Center for Biotechnology Information (NCBI) genome database through BLASTP (47). Homologous proteins with different levels of identity in other than $E$. coli species were selected and aligned by the multiple sequence alignment Clustal Omega (48), through which the percent identity was obtained. To further identify the conserved homologs of the proteins we used Jalview sequence alignment tool (49).

\section{Statistical analysis}

Analysis of the data was conducted by using GraphPad Prism 7 software (Version 7.0d). For muralytic assays, the activity of each soluble lysate fraction was tested in triplicate and means of activity was compared with the average activity of soluble lysate fraction of cells carrying an empty vector. The significance of muralytic activity was assessed with Unpaired-Samples t-test using 95\% confidence interval for the mean difference. The same software was used to analyze results from the growth inhibition assays, using the optical density $\left(\mathrm{OD}_{655}\right)$ of the bacterial growth after incubation with the soluble lysate fraction of each protein compared to the optical density of cells grown after treatment with soluble lysate fraction of cells carrying an empty vector. For the bactericidal assay, all bacterial counts were converted to log-scale and means and standard deviations were calculated 
380 afterwards. Bactericidal activity was tested in triplicate in three independent experiments. Decimal 381 reductions of cells were calculated by the difference between the average logarithmic 382 concentrations of cells treated with Innolysin\#6 and untreated cells, after incubation. The 383 significance of the decimal reductions of cells was assessed with Paired-Samples t-test using 95\% 384 confidence interval percentage.

\section{ACKNOWLEDJMENTS}

386 This work was supported by the Danish Council for Independent Research (4184-00109B). We 387 sincerely thank Lysando AG for supplying Artilysin-175 and our colleague Stephen Ahern for 388 supplying the $f h u A$ and $\operatorname{ton} B$ mutants of E. coli. Furthermore, we would like to thank Yilmaz Emre 389 Gencay and Hans Gerstmans for fruitful discussions. 


\section{REFERENCES}

391 1. Blair JM, Webber MA, Baylay AJ, Ogbolu DO, Piddock LJ. 2015. Molecular mechanisms of antibiotic resistance. Nat Rev Microbiol 13:42-51. https://doi.org/10.1038/nrmicro3380.

2. Chaturongakul S, Ounjai P. 2014. Phage-host interplay: examples from tailed phages and Gram-negative bacterial pathogens. Frontiers in Microbiology 5:442. https://doi.org/10.3389/fmicb.2014.00442.

3. Samson JE, Magadan AH, Sabri M, Moineau S. 2013. Revenge of the phages: defeating bacterial defences. Nat Rev Micro 11:675-687. https://doi.org/10.1038/nrmicro3096.

4. Rakhuba DV, Kolomiets EI, Dey ES, Novik GI. 2010. Bacteriophage receptors, mechanisms of phage adsorption and penetration into host cell. Pol J Microbiol 59:145-155.

5. Plancon L, Janmot C, Le Maire M, Desmadril M, Bonhivers M, Letellier L, Boulanger P. 2002. Characterization of a high-affinity complex between the bacterial outer membrane

6. Mondigler M, Vögele RT, Heller KJ. 1995. Overproduced and purified receptor binding protein pb5 of bacteriophage T5 binds to the T5 receptor protein FhuA. FEMS Microbiol Lett 130:293-300. https://doi.org/10.1111/j.1574-6968.1995.tb07734.x.

7. Ferguson AD, Hofmann E, Coulton JW, Diederichs K, Welte W. 1998. Siderophoremediated iron transport: crystal structure of FhuA with bound lipopolysaccharide. Science 282:2215-2220. https://doi.org/10.1126/science.282.5397.2215.

$411 \quad$ 8. Locher KP, Rees B, Koebnik R, Mitschler A, Moulinier L, Rosenbusch JP, Moras D. 1998. Transmembrane Signaling across the Ligand-Gated FhuA Receptor: Crystal 
Structures of Free and Ferrichrome-Bound States Reveal Allosteric Changes. Cell 95:771778. https://doi.org/10.1016/S0092-8674(00)81700-6.

9. Flayhan A, Wien F, Paternostre M, Boulanger P, Breyton C. 2012. New insights into pb5, the receptor binding protein of bacteriophage $\mathrm{T} 5$, and its interaction with its Escherichia coli receptor FhuA. Biochimie 94:1982-1989.

10. Böhm J, Lambert O, Frangakis AS, Letellier L, Baumeister W, Rigaud JL. 2001. FhuA-mediated phage genome transfer into liposomes: A cryo-electron tomography study. Curr Biol 11:1168-1175. https://doi.org/10.1016/S0960-9822(01)00349-9.

11. Oliveira H, Melo LD, Santos SB, Nobrega FL, Ferreira EC, Cerca N, Azeredo J, Kluskens LD. 2013. Molecular aspects and comparative genomics of bacteriophage endolysins. J Virol 87:4558-4570. https://doi.org/ 10.1128/JVI.03277-12. OA. 2009. Identification and characterization of the metal ion - dependent 1 - alanoyl - d glutamate peptidase encoded by bacteriophage T5. FEBS journal 276:7329-7342. https://doi.org/10.1111/j.1742-4658.2009.07443.x.

13. Schmelcher M, Loessner MJ. 2016. Bacteriophage endolysins: applications for food safety. Curr Opin Biotechnol 37:76-87. https://doi.org/10.1016/j.copbio.2015.10.005.

14. Briers Y, Walmagh M, Van Puyenbroeck V, Cornelissen A, Cenens W, Aertsen A, 
15. Lukacik P, Barnard TJ, Keller PW, Chaturvedi KS, Seddiki N, Fairman JW, Noinaj that targets Gram-negative pathogens. Proceedings of the National Academy of Sciences 109:9857-9862. https://doi.org/10.1073/pnas.1203472109.

16. Yan G, Liu J, Ma Q, Zhu R, Guo Z, Gao C, Wang S, Yu L, Gu J, Hu D, Han W, Du R, Yang J, Lei L. 2017. The N-terminal and central domain of colicin A enables phage lysin to lyse Escherichia coli extracellularly. Antonie Van Leeuwenhoek 110:1627-1635. https://doi.org/10.1007/s10482-017-0912-9.

17. Mondigler M, Holz T, Heller KJ. 1996. Identification of the Receptor-Binding Regions of

18. Argos P. 1990. An investigation of oligopeptides linking domains in protein tertiary structures and possible candidates for general gene fusion. J Mol Biol 211:943-958. https://doi.org/10.1016/0022-2836(90)90085-Z.

19. Schleifer KH, Kandler O. 1972. Peptidoglycan types of bacterial cell walls and their

20. Briers Y, Walmagh M, Grymonprez B, Biebl M, Pirnay J-P, Defraine V, Michiels J,

21. Schirmeier E, Zimmermann P, Hofmann V, Biebl M, Gerstmans H, Maervoet VE, Briers Y. 2017. Inhibitory and bactericidal effect of Artilysin((R)) Art-175 against colistin- 
resistant mcr-1-positive Escherichia coli isolates. Int J Antimicrob Agents. https://doi.org/10.1016/j.ijantimicag.2017.08.027.

461 22. Killmann H, Videnov G, Jung G, Schwarz H, Braun V. 1995. Identification of receptor binding sites by competitive peptide mapping: phages T1, T5, and phi 80 and colicin $\mathrm{M}$ bind

23. Llamas MA, Sparrius M, Kloet R, Jimenez CR, Vandenbroucke-Grauls C, Bitter W. 2006. The heterologous siderophores ferrioxamine B and ferrichrome activate signaling pathways in Pseudomonas aeruginosa. J Bacteriol 188:1882-1891.

H, Pattus F. 2005. Crystal Structure at High Resolution of Ferricpyochelin and its Membrane Receptor FptA from Pseudomonas aeruginosa. J Mol Biol

25. Cobessi D, Celia H, Folschweiller N, Schalk IJ, Abdallah MA, Pattus F. 2005. The crystal structure of the pyoverdine outer membrane receptor FpvA from Pseudomonas aeruginosa at 3.6 angstroms resolution. J Mol Biol 347:121-134.

26. Bonhivers M, Ghazi A, Boulanger P, Letellier L. 1996. FhuA, a transporter of the Escherichia coli outer membrane, is converted into a channel upon binding of bacteriophage T5. The EMBO Journal 15:1850-1856. https://doi.org/10.1002/j.1460-2075.1996.tb00535.x. diffusion channel through the outer membrane of Escherichia coli. The EMBO Journal 12:3007-3016. 
28. Edgar R, Rokney A, Feeney M, Semsey S, Kessel M, Goldberg Marcia B, Adhya S,

Oppenheim Amos B. 2008. Bacteriophage infection is targeted to cellular poles. Mol

Microbiol 68:1107-1116. https://doi.org/10.1111/j.1365-2958.2008.06205.x.

29. Erickson HP. 2009. Size and Shape of Protein Molecules at the Nanometer Level

Determined by Sedimentation, Gel Filtration, and Electron Microscopy. Biol Proced Online

11:32-51. https://doi.org/10.1007/s12575-009-9008-x.

30. Shavrina MS, Zimin AA, Molochkov NV, Chernyshov SV, Machulin AV,

Mikoulinskaia GV. 2016. In vitro study of the antibacterial effect of the bacteriophage T5

thermostable endolysin on Escherichia coli cells. J Appl Microbiol 121:1282-1290.

31. Walmagh M, Briers Y, Santos SBd, Azeredo J, Lavigne R. 2012. Characterization of

Modular Bacteriophage Endolysins from Myoviridae Phages OBP, 201 2-1 and PVP-SE1.

PLoS One 7:e36991. https://doi.org/10.1371/journal.pone.0036991.

32. Walmagh M, Boczkowska B, Grymonprez B, Briers Y, Drulis-Kawa Z, Lavigne R.

2013. Characterization of five novel endolysins from Gram-negative infecting bacteriophages. Appl Microbiol Biotechnol 97:4369-4375. https://doi.org/10.1007/s00253-

33. Gerstmans H, Criel B, Briers Y. 2017. Synthetic biology of modular endolysins. Biotechnology Advances. https://doi.org/10.1016/j.biotechadv.2017.12.009.

\section{Hermoso JA, Monterroso B, Albert A, Galán B, Ahrazem O, García P, Martínez-}

Ripoll Mn, García JL, Menéndez M. 2003. Structural Basis for Selective Recognition of https://doi.org/10.1016/j.str.2003.09.005. 
35. Pawelek PD, Croteau N, Ng-Thow-Hing C, Khursigara CM, Moiseeva N, Allaire M, Coulton JW. 2006. Structure of TonB in complex with FhuA, E. coli outer membrane receptor. Science 312:1399-1402. https://doi.org/10.1126/science.1128057.

36. Shin H, Lee JH, Kim H, Choi Y, Heu S, Ryu S. 2012. Receptor diversity and host interaction of bacteriophages infecting Salmonella enterica serovar Typhimurium. PLoS

37. Labrie SJ, Samson JE, Moineau S. 2010. Bacteriophage resistance mechanisms. Nature Reviews Microbiology 8:317. https://doi.org/10.1038/nrmicro2315.

38. Yang JH, Bening SC, Collins JJ. 2017. Antibiotic efficacy-context matters. Curr Opin Microbiol 39:73-80. https://doi.org/10.1016/j.mib.2017.09.002.

39. Meng X, Liu X, Zhang L, Hou B, Li B, Tan C, Li Z, Zhou R, Li S. 2016. Virulence characteristics of extraintestinal pathogenic Escherichia coli deletion of gene encoding the outer membrane protein X. The Journal of Veterinary Medical Science 78:1261-1267. https://doi.org/10.1292/jvms.16/0071.

40. Atkinson S, Williams P. 2016. Yersinia virulence factors - a sophisticated arsenal for combating host defences. F1000Research 5:F1000 Faculty Rev-1370. https://doi.org/10.12688/f1000research.8466.1.

522 41. Aabo S, Rasmussen OF, Roseen L, Sørensen PD, Olsen JE. 1993. Salmonella identification by the polymerase chain reaction. Mol Cell Probes 7:171-178. https://doi.org/10.1006/mcpr.1993.1026.

42. Holloway BW. 1955. Genetic Recombination in Pseudomonas aeruginosa. Microbiology 13:572-581. https://doi.org/10.1099/00221287-13-3-572. 
43. Kim M, Kim S, Park B, Ryu S. 2014. Core Lipopolysaccharide-Specific Phage SSU5 as an Auxiliary Component of a Phage Cocktail for Salmonella Biocontrol. Appl Environ Microbiol 80:1026-1034. https://doi.org/10.1128/AEM.03494-13.

44. Datsenko KA, Wanner BL. 2000. One-step inactivation of chromosomal genes in Escherichia coli K-12 using PCR products. Proceedings of the National Academy of Sciences 97:6640-6645. https://doi.org/10.1073/pnas.120163297.

45. Lavigne R, Briers Y, Hertveldt K, Robben J, Volckaert G. 2004. Identification and

46. Briers $\mathbf{Y}$, Lavigne $\mathbf{R}$ 61:2753-2759. https://doi.org/10.1007/s00018-004-4301-v. accurate quantification of murein hydrolase activity in high-throughput assays. J Biochem

47. NCBI Resource Coordinators. . 2013. Database resources of the National Center for Biotechnology Information. Nucleic Acids Res 41:D8-D20. https://doi.org/10.1093/nar/gks1189.

48. Sievers F, Wilm A, Dineen D, Gibson TJ, Karplus K, Li W, Lopez R, McWilliam H, http://doi.org/10.1038/msb.2011.75.

49. Waterhouse AM, Procter JB, Martin DMA, Clamp M, Barton GJ. 2009. Jalview Version 2-a multiple sequence alignment editor and analysis workbench. Bioinformatics 


\section{FIGURE LEGENDS}

551 FIG 1 Visual representation of Innolysins. Phage T5 endolysin (T5 Lys) was fused with the whole phage $\mathrm{T} 5$ receptor binding protein, $\mathrm{Pb} 5$ or the binding domain of $\mathrm{Pb} 5\left(\mathrm{~Pb} 5_{1-488}\right)$. Fusion was conducted without linkers (1 - 4) or with linkers (L1 or L2) $(5$ - 12) with T5 Lys located in the Nterminus $(1-2 ; 5-8)$ or C-terminus $(3-4 ; 9-12)$ of the engineered proteins.

FIG 2 Muralytic activity of Innolysins. Soluble fractions of the cleared lysate of the engineered proteins (1-12, see Fig. 1) were screened for ability to degrade peptidoglycan of $P$. aeruginosa PAO1 and compared to the activity of soluble lysate of cells carrying the empty vector, pVTSD2. Phage T5 endolysin and receptor binding protein, $\mathrm{Pb5}$ were used as a positive and a negative control, respectively. Average muralytic activities $(\mathrm{U} / \mathrm{ml})$ were estimated based on triplicates. * Significant muralytic activity at $\mathrm{P}<0.05$.

FIG 3 Growth of E. coli after treatment with Innolysins. Soluble induced fractions of muralytically active engineered proteins (see Fig. 2) were screened for the ability to inhibit growth of E. coli ATCC11303. Art-175 was provided by Lysando AG (20) and used as a positive control. Phage T5 endolysin and receptor binding protein, $\mathrm{Pb} 5$ were used as negative controls. Growth inhibition was detected as the absence of growth $\left(\mathrm{OD}_{655 \mathrm{~nm}}\right)$ of cells treated with an Innolysin in comparison to the negative control (growth of ATCC11303 cells treated with supernatant lysates of cells carrying the empty vector, pVTSD2) after incubation for 18 hours at $37^{\circ} \mathrm{C}$. * Significant bacterial growth inhibition at $\mathrm{P}<0.05$.

FIG 4 Bactericidal activity of the Innolysin against E. coli. Average logarithmic reductions of different E. coli strains, after incubation with Innolysin\#6 for $30 \mathrm{~min}$ at $20^{\circ} \mathrm{C}$, compared to the

571 untreated cells. The average reduction was calculated based on triplicates of three independent experiments. * Significant reduction at $\mathrm{P}<0.05$. 
573 FIG 5 Morphological changes of $E$. coli treated with Innolysin\#6. The effect of Innolysin\#6 on 574 BL21 (Fig 5B-D) and BL21 $4 f h u A$ (F) was compared to the untreated BL21 (Fig 5A) and 575 BL21 4 fhuA (Fig 5E), respectively. Cytosol leakage mainly at poles (Fig. 5B, arrow 1); cell debris 576 likely due to cell lysis (Fig. 5C, arrow 2) and separation of the outer membrane (Fig. 5D, arrow 3) 577 and inner membrane (Fig. 5D, arrow 4) were observed in the majority of BL21 cells treated with the 578 Innolysin. Such dramatic changes were not observed in BL21 4 fhuA cells after incubation with 579 Innolysin\#6 (Fig. 5F).

580 FIG 6 Bactericidal spectrum of the Innolysin. Average logarithmic reductions of different species, 581 after incubation with Innolysin\#6 for $30 \mathrm{~min}$ at $20^{\circ} \mathrm{C}$, compared to the untreated cells. The average 582 reduction was calculated based on triplicates of three independent experiments. * Significant 583 reduction at $\mathrm{P}<0.05$.

584 FIG 7 Conservation of FhuA homologs in Gram-negative bacteria. FhuA of E. coli BL21 585 (WP_000124402.1) was used as a reference to search for homologous proteins in other than E. coli 586 species. FhuA of Shigella sonnei (WP_094317049.1) and Salmonella Typhimurium LT2c 587 (NP_459196.1) are aligned with FhuA of E. coli BL21 (WP_000124402.1). FhuA protein sequence 588 of E. coli ECOR4 (locus tag ESC_AA8779AA_AS_03052, PRJEB2879) is also aligned with FhuA 589 of E. coli BL21 to confirm the high conservation between the FhuA of both $E$. coli strains that were 590 used. Amino acids are colored based on the level of conservation with transition of the orange to 591 grey to represent increased conservation. A 5.5 threshold was used for illustrating the conservation 592 of homologs by Jalview sequence alignment tool. The red box highlights the amino acids 593 responsible for the formation of the surface-exposed part of loop L4 of FhuA (WP_000124402.1) in 594 E. coli BL21. 


\section{SUPPLEMENTAL MATERIAL}

\section{FIG S1 Alignment of $E$. coli BL21 FhuA with homologous proteins of $P$. aeruginosa.}

FiuA (NP_249161.1), FoxA (NP_251156.1), FptA (NP_252911.1), FpvA (NP_251088.1) and FpvB

(NP_252857.1) of Pseudomonas aeruginosa PAO1 were aligned with E. coli BL21 FhuA (WP_000124402.1). Amino acids are colored based on the level of conservation with transition of orange to grey to represent higher conservation. Conservation with no threshold was used by Jalview sequence alignment tool. The red box highlights the alignment of $P$. aeruginosa homologous proteins to the amino acid sequence of FhuA responsible for the formation of the surface-exposed part of loop L4 in E.coli BL21.

\section{Table S1: Primers used for PCR amplification in cloning}

For generating mutations in E. coli strains, primers were designed with regions of homology to the target genes (indicated in bold). To engineer recombinant proteins, oad and lys genes of phage T5 encoding $\mathrm{Pb} 5$ and phage T5 endolysin, respectively, were used for fusion, whereas linkers L1: AGAGAG and L2: GAGAGAGAGAGAGA were created as primer cassettes. The recognition sites of BsaI (highlighted in grey) were used for cloning into pNICBsa4 vector.

\section{Table S2: Percent matrix identity of BL21 FhuA homologs}

Percent identity between homologous proteins and E. coli BL21 FhuA (WP_000124402.1) was calculated by sequence alignment Clustal Omega. Full-length FhuA protein sequences of E. coli BL21 (WP_000124402.1), E. coli ECOR4 (locus tag ESC_AA8779AA_AS_03052, PRJEB2879), Shigella sonnei (WP_094317049.1) and Salmonella Typhimurium LT2c (NP_459196.1) were used for constructing the identity matrix. Furthermore, homologous proteins of Pseudomonas aeruginosa PAO1, including FiuA (NP_249161.1), FoxA (NP_251156.1), FptA (NP_252911.1), FpvA (NP_251088.1) and FpvB (NP_252857.1), were tested for the identity level compared to E. coli BL21 FhuA (WP_000124402.1). 
1.

T5 Lys

Pb5

2. T5 Lys $\mathrm{Pb5}_{1-488}$

3.

4

6. \begin{tabular}{|l|l|l|}
\hline T5 Lys & L1 & $\mathrm{Pb5}_{1-488}$ \\
\hline
\end{tabular}

7. T5 Lys L2 $\quad$ Pb5

8. T5 Lys L2 $\quad \mathrm{Pb5}_{1-488}$

9. Pb5 L1 T5 Lys

10.

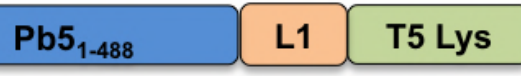

11. Pb5 L2 T5 Lys

12.

$\mathrm{Pb}_{1-488}$

L2 T5 Lys 


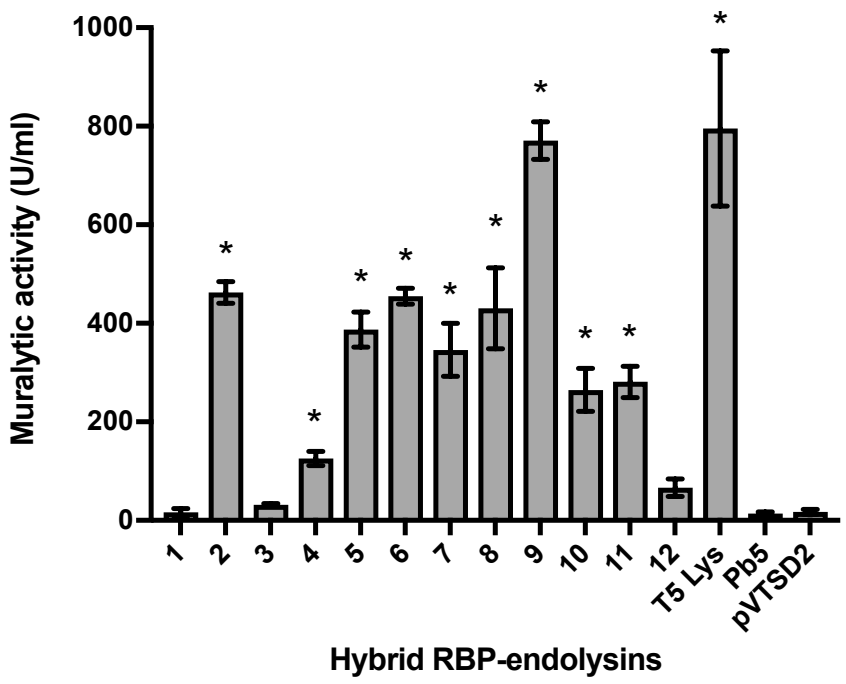




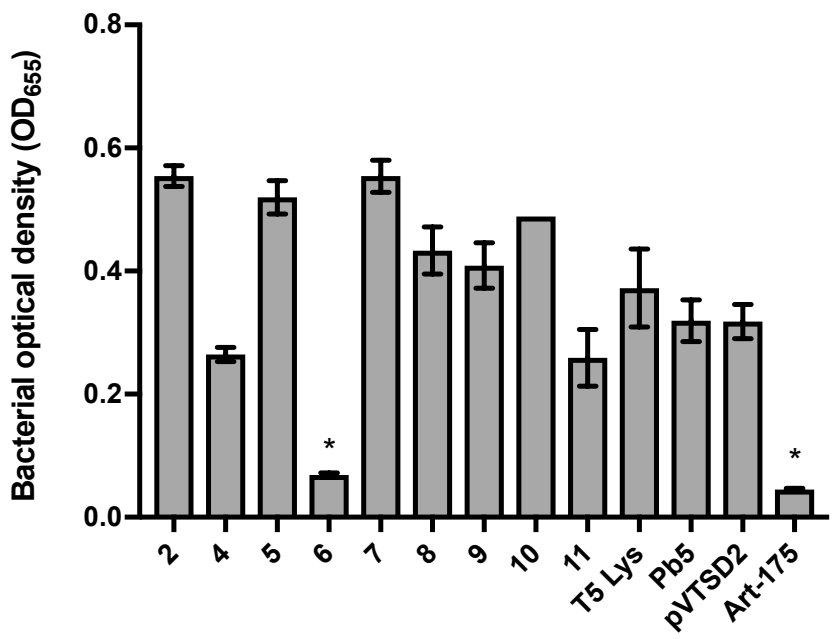

Hybrid RBP-endolysins 


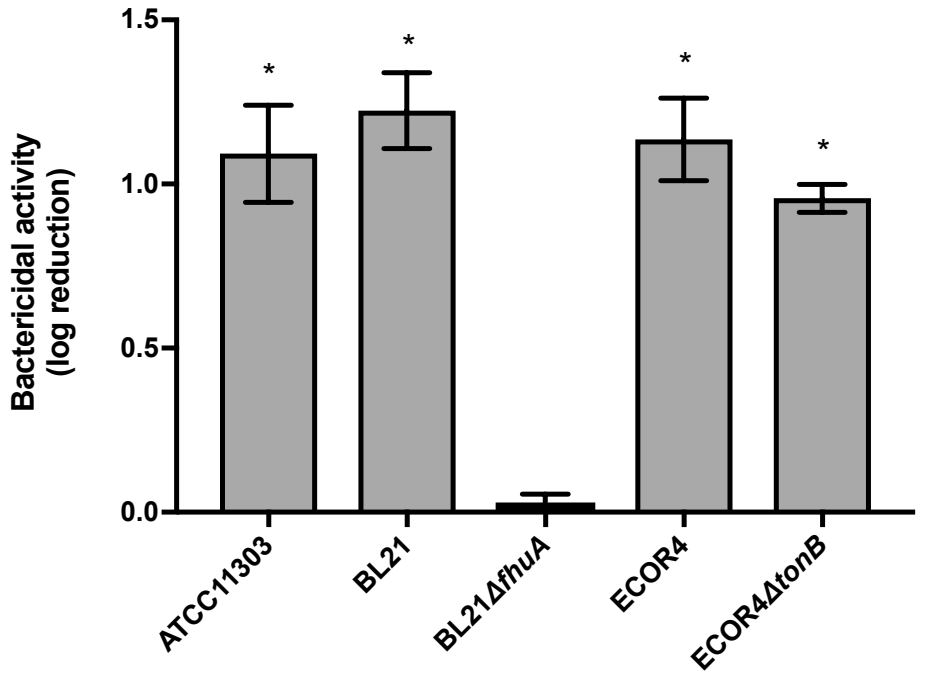

E. coli strains 


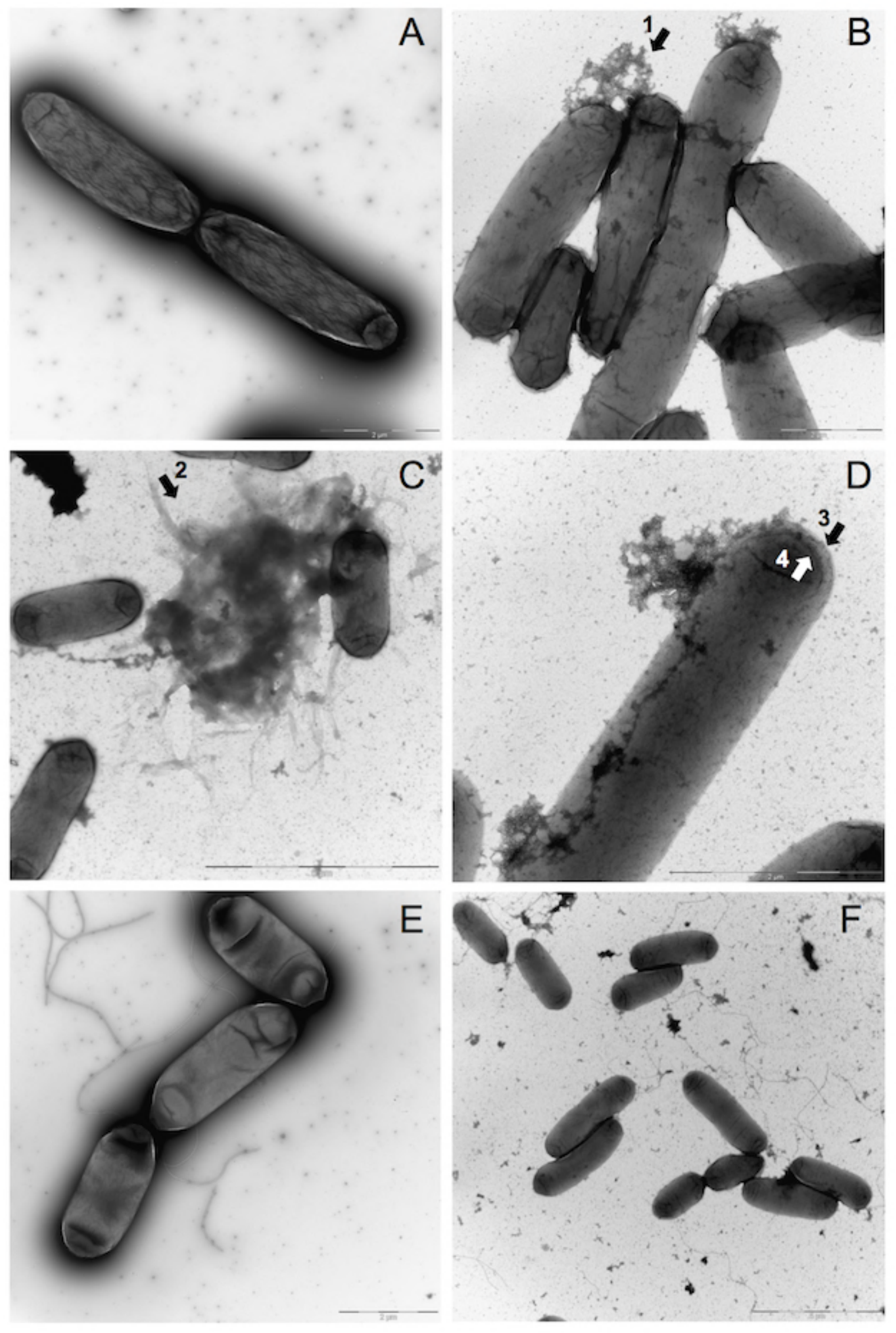




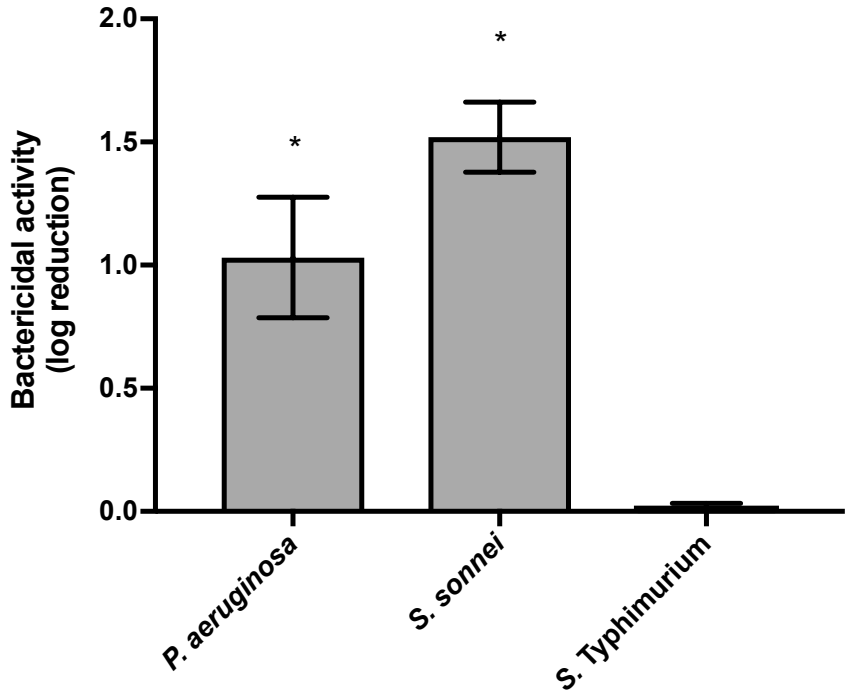

Bacterial species 
S. $L$ L $L T 2 C / 1-729$

S. sonnei//. 747

E.c. $\quad B L 21 / 1-7$

S. $t . L T 2 c / 1-72$

S._sonnei/l-7.7.

$E, C . B L 21 / 1$.
$E C O R 4 / 1-747$

S. $L . L T 2 C / 1-729$

S._Sonnei/l-747

E. C. B BL21/1-745
ECOR $4 / /-747$

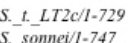

E. C. BL2I///

$E \overline{C O R} 4 / 1-747$

S. $L$ LLT2C/1.729

E. c. c. BLL21/1-7

ECOR4/I-747

S. $t . \angle T 2 C / 1-7$.

S. sonnei/l-74

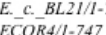

S. $t . L T 2 C / 1.729$

S._oonei/l-747

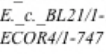

1 MARLKTAQPNSS
1 MAR SKTAQPKHS
1 MARSKTAQPKHS

HMARSKT QPKHS LKI AVVVATAVSGMSVYAQAAVEPKEDTI TVTAAPAPQESAWGPAATI AARQSATGTKTDTPI QKVPQSI SVVTAEEMALHQPKSVKEALSYTPGVSVGT II

114 RGASNTYDFVII RGF S SVGLS QNNYLDGLKLQGNFYNDAV I DPYMLER VELMRGPT SVLYGKSNPGGI I SMVSKRPTTEPLKEIQFKMGTDNLFQTGFDFSDSLDDNGEF S YR 226 14 RGASNTYDHLIIRGFAAEGOSONNYLNGLKLOGNFYNDAVI DPYMLERAEIMRGPVSVLYGKS SPGGLLNMVSKRPTTEPLKEVOFKAGTDSLFOTGFDF DSLDDDGVYSYR 114 RGASNTYDHLI IRGFAAGQSQNNYLNGLKLOGNYNDAA I DPYMLERAEIMRGPVSVLYGSSPGGLLNMVSKRPTTEPLKEVOFKAGTDSLFOTGFDFDALDDDGVYS R 14 RGASNTYDHLI IRGFAAEGQSQNNYLNGLKLQGNFYNAVI DPYMLERAEIMRGPVSVLYGS SPGGLLNMVSKRPTTELKEVQFKAGTDSLFQTGFDF DALDDDGVYYR

227 LTGLAR S TNEQQKS SESQRYA IAPSFTWRPDEKTNFTFLSYFQNEPETGYYGWLPKEGTVEPLPNGKRLPTDFNEGASNNTYSRNEKMVGYSFEHGFDTFTVRQNLRFVEMK 227 LTGLAR SANAQQKGSEEQRYA APAFTWR PDKTNFTFLSYFQNEPETGYYGWLPKEGTVEPLPNGKRLPTDFNEGAKNNTYSNEKMVGYSFDHEFNDTFTVRNLRFAENK 339

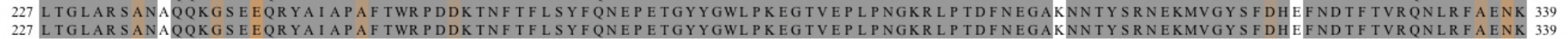

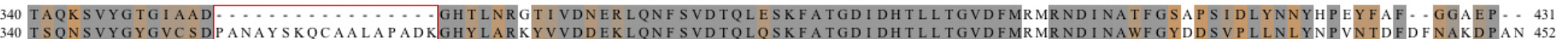
340 TSONSVYGYGVC SDPANAYSKOCAALAPADKGHYLARKYVVDDEKLONFSVDTOLOSKFATGDIDHTLLTGVDFM. - RNDINAWFGYDDSPLLNLYNPVNTDFDFNAKDPAN 450 340 T SQNSVYGYGVC SDPANAYSKQCAALAPADKGHYLARKYVVDDEKLQNF SVDTQLQSKFATGDI DHT LLTGVDFMRMRND I NAWF GYDDSVPLLNLYNPVNTDFDFNAKDPAN 452 $432 \ldots . .$. - OMNESKOTGLYVODOAEWNKWVFTLGGRYDWSKOATTVRONSTTPTEGY IERNDHOFTWRGGVNYVFDNGISPYFSYSOSFEPSAFDLWSTPRVSYKPSKGEOYEAGV 540 453 SGPYR I LNKQKQTGVYVQDQAQWDKVLVTLGGRYDWADQESLNRVAGTTD.... KRDDKQFTWRGGVNYLFDNGVTPYFSYSESFEPSS

541 KYVPKDMPVVVTGAVYOLTKTNNLTADP TNPLAQVPAGEIRARGVELEAKAALTAN INMTASYTYTDAEYTKDTNLKGNTPEOVPEHMAS LWGDYTFNEGPLSGLTLGTGGR F 559 KYVPEDRP I VVTGAVYNLTKNNNLMADPEGSFF VVEGEIRARGVEIEAKAALSASVNVVGSYTYTDAEYTTDTTYKGNTPAQVPKHMASLWADYTFFDGPLSGLTLGTGGRY 557 KYVPEDRP IVVTGAVYNLTK TNNLMADPEGSFFSVEGGEIRARGVE I EAKAALSAS VNVVGSYTYTDAEYTTDTTYKGNTPAQVPKHMASLWADYTFFDGPLSGLTLGTGGR 559 KYVPEDRP I VVTGAVYNLTKTNNLMADPEGSFF SVEGGEIRARGVEIEAKAALSASVNVVGYTYTDAEYTTDTTYKGNTPAQVPKHMASLWADYTFFDGPLSGLTLGTGRY

654 IGSSYGDPANSFKVGSAAVMDAVVKYDLARFGMAGS I AVNVNNLLDREYVASCFQTYGCFWGAERQVVATATFRF

672 TGSSYGDPANSFKVGSYTVVDALRYDLAR VGMAGSNVALHVNNLFDREYVASCFNTYGCFWGAERQVVATATFRF

670 TGSSYGDPANSFKVGSYTVVALVRYDLAR VGMAGSNVALHVNNLFDREYVASCFNTYGCFWGAERQVVATATFRF

\author{
113 \\ 113
} 31
452
450
452
540
558
556
558 653 $\left\{\begin{array}{l}671 \\ 669 \\ 671\end{array}\right.$ $\begin{array}{ll}Y & 669 \\ \text { Y } & 671\end{array}$

$$
\begin{aligned}
& 729 \\
& 747 \\
& 745 \\
& 747
\end{aligned}
$$

